\title{
A Brief Review on Mechanisms of Gene Regulation and Pathogenomics
}

\section{Carl K Edwards*}

Professor of Medicine, University of Colorado Denver, USA

Dr. Francis S. Collins, M.D., Ph.D., who is currently the Director of the National Institutes of Health (NIH) in the United States, is a well-known physician-geneticist noted for his landmark discoveries of disease genes and his leadership of the International Human Genome Project, which culminated in April 2003 with the completion of a finished sequence of the "human DNA instruction book" [1,2]. Although it has been more than 10 years since the human DNA sequence was published by Dr. Collins and his large collaborative group, it seems like only yesterday when we learned about the incredible task of sequencing the entire human genome. This spectacular research was conducted in collaboration with Dr. Craig Venter and his group at Celera [3]. At the time, I remember many editorials in scientific journals questioning, sometimes negatively, the significance of this achievement, and what was likely to result from these efforts.

Before coming to the NIH, Dr. Collins was a Howard Hughes Medical Institute investigator at the University of Michigan. He is an elected member of the Institute of Medicine and the National Academy of Sciences, was awarded the Presidential Medal of Freedom in November 2007, and received the National Medal of Science in 2009. He served as director of the National Human Genome Research Institute at the NIH from 1993-2008. Dr. Collins, who was nominated by President Barack Obama on July 8, 2009, and was unanimously confirmed by the U.S. Senate on August 7, was officially sworn in on Monday, August 17, 2009 as the $16^{\text {th }}$ director of the National Institutes of Health (NIH). In that role he oversees the work of the largest supporter of biomedical research in the world, spanning the spectrum from basic to clinical research.

In this special issue of the Journal of Bioanalysis and Biomedicine, we are proudly focusing on several advanced molecular technologies, and our issue is entitled "Mechanisms of Gene Regulation and Pathogenomics". In this issue, we are presenting the findings of wellknown investigators who are located at several highly-recognized laboratories from around the world who are reporting their experimental findings in human disease-related research using advanced genomic and gene expression technologies that arguably arose from these original human genome studies published more than a decade ago. Therefore, it seems fitting that we mention the contributions of Dr. Collins here, as well his numerous world-wide collaborators on these large-scale projects, since he and his collaborators have been recognized leaders towards the promotion of novel and cutting-edge genetic techniques to study the molecular regulation of disease causing genes and how these important genes promote acute and chronic diseases in man $[4,5]$.

Since the dual publications in Nature and Science of the human genome sequence, Dr. Collins has continued to advance molecular techniques which have greatly added our understanding of the pathology and pathgenomic mechanisms leading to disease. For instance, in 2004, Dr. Collins, along with several other investigators began the Mouse Knockout Project [6]. Mouse knockout technology provides a powerful means of elucidating gene function in vivo, and a publicly available genome-wide collection of mouse knockouts would be "significantly enabling for biomedical discovery". At that time, published knockouts existed for only about $10 \%$ of mouse genes.
Similarly, many of the mouse knockout models were limited in utility because they had not been made or phenotyped in standardized ways, and many were not freely available to researchers. Therefore, these efforts attempted to harness new technologies and efficiencies of production to mount a high-throughput international effort to produce and phenotype knockouts for all mouse genes, and place these resources into the public domain [6]. In 2007, Dr. Collins, along with the International Mouse Knockout Consortium, updated their progress to outline that three major mouse knockout programs were underway worldwide, working together to mutate all protein-encoding genes in the mouse using a combination of gene trapping and gene targeting in mouse embryonic stem (ES) cells [7]. These authors concluded that "although the current emphasis is on production of this valuable resource, there are significant efforts to facilitate program coordination, to enhance the availability of this resource, and to plan for future efforts in mouse genetics research" [7]. Finally, in 2009, Dr. Collins was part of an international group to promote the Mammalian Gene Collection (MGC), which has sought to provide at least one full-protein-coding sequence cDNA clone for every human and mouse gene with a RefSeq transcript, and at least 6200 rat genes [8]. The MGC cloning effort initially relied on random expressed sequence tag screening of cDNA libraries. These investigators demonstrated that the MGC now contains clones with the entire protein-coding sequence for $92 \%$ of human and $89 \%$ of mouse genes with curated RefSeq (NM-accession) transcripts, and for $97 \%$ of human and $96 \%$ of mouse genes with curated RefSeq transcripts that have one or more PubMed publications, in addition to clones for more than 6300 rat genes [8]. Most importantly, these high-quality MGC clones and their sequences are accessible without restriction to researchers worldwide.

Finally, one of the enduring legacies of Dr. Collins and his many accomplishments and initiatives at NIH is the creation of the National Center for Advancing Translational Sciences (NCATS), a new institute at the NIH which aims to shorten the time that novel discoveries made in the laboratory can be "translated" into effective medicines. The mission of the NCATS at the NIH is to catalyze the generation of innovative methods and technologies that will enhance the development, testing and implementation of diagnostics and therapeutics across a wide range of human diseases and conditions [9]. Scientists practicing clinical and translational research strive to transform laboratory discoveries into new therapies for patients. It can take more than a decade, however, before a basic scientific finding can advance through preclinical and clinical studies to result in a new treatment, medical device or prevention method. Accelerating this

${ }^{*}$ Corresponding author: Carl K Edwards, Professor of Medicine, University of Colorado Denver, USA, E-mail: drcarledwards@gmail.com

Received April 19, 2013; Accepted April 20, 2013; Published April 22, 2013

Citation: Edwards CK (2013) A Brief Review on Mechanisms of Gene Regulation and Pathogenomics. J Bioanal Biomed S3: e001. doi:10.4172/1948-593X.S3-e001

Copyright: () 2013 Edwards CK. This is an open-access article distributed under the terms of the Creative Commons Attribution License, which permits unrestricted use, distribution, and reproduction in any medium, provided the original author and source are credited. 
process is a top priority for NCATS as part of its mission to catalyze the generation of innovative methods and technologies that will result in therapeutics to meet unmet medical needs and conditions. However, researchers throughout the world face common barriers in clinical and translational research, including:

- Increased research costs and complexity;

- A shortage of information systems;

- Increased regulatory burdens;

- Low patient recruitment and retention in clinical research studies;

- Difficulties in recruiting, mentoring and retaining a critical mass of qualified clinical and translational investigators.

Barriers such as these can cause delays in achieving ideal end results. NCATS is committed to improving the process of bringing new treatments, preventions and diagnostics to patients faster and more economically. The NCATS Division of Clinical Innovation is charged with transforming the translational research process. The Clinical and Translational Science Awards (CTSA) program, which is part of this division, funds a national consortium of medical research institutions dedicated to improving clinical and translational research. This program serves as an essential component in addressing these research challenges. Clinical trials and research studies with patients also play an important role. Researchers need access to tools, expertise and resources that can expedite this often lengthy process while ensuring patient safety. NIH offers many tools that can provide assistance to researchers who need help designing clinical trials, recruiting appropriate patients for their studies and engaging the community in the research process.
In summary, I would like to take this opportunity to applaud these efforts by Dr. Collins and his extraordinary leadership towards these initiatives since they demonstrate what large - scale research collaborations can accomplish toward finding new cures for human diseases. Furthermore, his efforts represent a perfectexample for us all as to how we can work together more effectively in our individual research programs to accomplish greater goals for the discovery of novel medicines. Through the use of cutting-edge molecular techniques and medical technologies we can collectively change the way that we identify and treat human illnesses to improve patient's lives.

\section{References}

1. Lander ES, Linton LM, Birren B, Nusbaum C, Zody MC, et al. (2001) Initia sequencing and analysis of the human genome. Nature 409: 860-921.

2. Guttmacher AE, Collins FS (2002) Genomic Medicine - A Primer. N Engl J Med 347: 1512-1520

3. Venter JC, Adams MD, Myers EW, Li PW, Mural RJ, et al. (2001) The sequence of the human genome. Science 291: 1304-1351.

4. Collins FS (2003) Genome research: the next generation. Cold Spring HarbSymp Quant Biol 68: 49-54.

5. Clarke L, Zheng-Bradley X, Smith R, Kulesha E, Xiao C, et al. (2012) The 1000 genomes project: data management and community access. Nat Methods 9 $459-462$.

6. Austin CP, Battey JF, Bradley A, Bucan M, Capecchi M, et al. (2004) The knockout mouse project. Nat Genet 36: 921-924.

7. International Mouse Knockout Consortium, Collins FS, Rossant J, Wurst W (2007) A mouse for all reasons. Cell 128: 9-13

8. MGC Project Team, Temple G, Gerhard DS, Rasooly R, Feingold EA et al. (2009) The completion of the Mammalian Gene Collection (MGC). Genome Res 19: 2324-2333.

9. http://www.ncats.nih.gov/research/cts/cts.html
This article was originally published in a special issue, Mechanisms and Gene Regulation : Normal and Pathogenomics handled by Editor(s). Dr. Carl Edwards, University of Colorado Denver, USA 